14,17

\title{
Особенности процессов переноса заряда в нанокомпозитах на основе полифениленоксида с фуллереном и эндофуллереном
}

\author{
(C) А.А. Кононов ${ }^{1}$, Н.А. Никонорова ${ }^{2}$, Р.А. Кастро ${ }^{1}$ \\ ${ }^{1}$ Российский государственный педагогический университет им. А.И. Герцена, \\ Санкт-Петербург, Россия \\ ${ }^{2}$ Институт высокомолекулярных соединений РАН, \\ Санкт-Петербург, Россия \\ E-mail: kononov_aa@icloud.com
}

Поступила в Редакцию 6 июня 2021 г.

В окончательной редакции 6 июня 2021 г.

Принята к публикации 9 июня 2021 г.

Представлены результаты исследования процессов переноса электрического заряда в полимерных нанокомпозитах на основе полифениленоксида с фуллереном $\mathrm{C}_{60}(1$ и $8 \%)$ и с эндометаллофуллереном $\mathrm{Fe} @ \mathrm{C}_{60}$ $(1 \%)$ в качестве нанонаполнителей. С использованием существующих теоретических моделей рассчитаны значения параметров переноса заряда, такие как концентрация носителей $N$, длина свободного пробега $R_{\omega}$

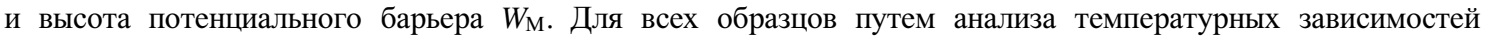
показателя степени степени $s$ определен тип проводимости.

Ключевые слова: перенос заряда, прыжковый механизм проводимости, квантово-механическое туннелирование, полимерные нанокомпозиты, фуллерен, эндометаллофуллерен.

DOI: 10.21883/FTT.2021.10.51461.135

\section{1. Введение}

Полимеры являются идеальными матрицами для создания новых материалов с заданными свойствами, в частности, для получения мембран широкого назначения. Мембраны используют в процессах концентрирования и фракционирования смесей, очистки продуктов от сопутствующих примесей, при регенерации ценных компонентов, для получения обессоленной и очищенной воды, при решении экологических задач. В последнее время хорошо зарекомендовали себя мембраны из полифениленоксида (ПФО), а также композиты на его основе [1-3]. Модификации ПФО различными видами наполнителей приводят к существенным изменениям его диэлектрических, структурных и диффузионных свойств. Для улучшения мембранных свойств широко внедряют аллотропные формы углерода, одной из которых является фуллерен $\left(\mathrm{C}_{60}\right)[4]$.

При модификации ПФО фуллереном $\mathrm{C}_{60}$ образуются нанокомпозиты с комплексами донорно-акцепторного типа. Изучение растворов этого комплекса реологическими и гидродинамическими методами показало [5], что связь ПФО с $\mathrm{C}_{60}$ является достаточно устойчивой, так какдаже при разбавлении комплекс не разделяется на компоненты, хотя и имеет место небольшое уменьшение характеристической вязкости и асимметрии формы сегментов ПФО. Методами масс-спектрометрического термического анализа и дифференциальной калориметрии показано, что добавка фуллерена в ПФО повышает его термостабильность [6]. При исследовании спектров фотолюминесценции установлено наличие молекулярных комплексов в пленках ПФО/ $\mathrm{C}_{60}$, содержащих до $2 \mathrm{wt} \%$ $\mathrm{C}_{60}$. При увеличении концентрации, начиная с 4\% значительная часть молекул $\mathrm{C}_{60}$ находится в несвязанном с молекулами ПФО состоянии [7].

Наряду с хорошо исследованными фуллеренами $\mathrm{C}_{60}$ представляют интерес т.н. эндоэдральные фуллерены, содержащие во внутренней полости фуллеренового каркаса атомы металлов и неметаллов. Такие включения изменяют электрофизические свойства молекулы фуллерена, а соответственно, и полимерного композита.

В настоящей работе исследованы процессы переноса заряда в полимерных нанокомпозитах на основе ПФО с фуллереном $\mathrm{C}_{60}$ и эндометаллофуллереном $\mathrm{Fe} @ \mathrm{C}_{60}$. Цель работы - выявить влияние наполнителей $\mathrm{C}_{60}$ и $\mathrm{Fe} @ \mathrm{C}_{60}$ на электрофизические свойства нанокомпозита.

\section{2. Методика эксперимента}

Полимерной матрицей служил ПФО с молекулярной массой $(\mathrm{MM})=178000 \mathrm{~g} / \mathrm{mol}$ и плотностью $1.06 \mathrm{~g} / \mathrm{cm}^{3}$. $\mathrm{B}$ качестве нанодобавки использовали фуллерен $\mathrm{C}_{60}$ и эндометаллофуллерен $\mathrm{Fe} @ \mathrm{C}_{60}$ с содержанием более 99.5 mass\% $\mathrm{C}_{60}$ (ООО „Фуллереновые технологии“, Россия). Композиты ПФО/С60 и ПФО/Fe@ $\mathrm{C}_{60}$ получали смешением растворов ПФО в хлороформе и фуллерена/эндофуллерена в толуоле. Пленки получали на поверхности целлофана в круглой форме, которую заполняли рассчитанным количеством $2 \%$-го раствоpa полимера. Толщина пленок составляла 30-100 $\mu \mathrm{m}$. В настоящей работе представлены результаты иссле- 
дования образцов следующего состава: ПФО/С $60(1 \%)$, ПФО/ $\mathrm{C}_{60(8 \%)}$, ПФО/Fе@ $\mathrm{C}_{60(1 \%)}$ и чистого ПФО. Выбор образцов определялся именно тем обстоятельством, что для ПФО/ $\mathrm{C}_{60(1 \%)}$ и ПФО/Fe $@ \mathrm{C}_{60(1 \%)}$ наполнитель находится в матрице полимера в молекулярно-диспергированном виде, когда между молекулами полимера и наполнителя есть химическая связь $[8,9]$. Дальнейшее увеличение содержания наполнителя (уже при 4\%) приводит к формированию кластеров фуллерена, которых в пленке ПФО/С $\mathrm{C}_{60(8 \%)}$ будет заведомо больше. Поэтому интересно было сопоставить электрофизические свойства нанокомпозитов с качественно различной структурой.

Измерения электропроводящих спектров были выполнены на диэлектрическом спектрометре „Concept-81“ (Novocontrol Technologies $\mathrm{GmbH}$ ). Для получения экспериментальных данных пленочные образцы помещали между латунными электродами (диаметр верхнего электрода $20 \mathrm{~mm}$ ). Для образцов систем ПФО, ПФО/С $60(1 \%)$, $\Pi \Phi \mathrm{O} / \mathrm{C}_{60(8 \%)}, \quad \Pi \Phi \mathrm{O} / \mathrm{Fe} @ \mathrm{C}_{60(1 \%)}$ в интервале частот $10^{-1}-10^{6} \mathrm{~Hz}$ и температур $-100-+250^{\circ} \mathrm{C}$ получены температурно-частотные зависимости действительной части комплексной проводимости $\sigma^{\prime}$. Точность поддержания температуры на образце составляла $\pm 0.5^{\circ} \mathrm{C}$. Haпряжение, подаваемое на образец, составляло $U=1.0 \mathrm{~V}$.

\section{3. Результаты и обсуждение}

Частотные зависимости действительной части комплексной проводимости $\sigma^{\prime}(f)$ в двойном логарифмическом масштабе для ПФО/С $60(1 \%)$ в интервале температур от 150 до $250^{\circ} \mathrm{C}$ представлены на рис. 1 .

В интервале температур от -100 до $150^{\circ} \mathrm{C}$ зависимости $\sigma^{\prime}(f)$ показывают линейный рост проводимости при увеличении частоты (рис. 2). Затем, при более высоких температурах, появляется излом (при частоте $f_{0}$ ) при переходе к частотно-независимой области $\sigma^{\prime}(f)$ на низких частотах. Частота излома $f_{0}$ на зависимости $\sigma^{\prime}(f)$ возрастает с ростом температуры. Для образцов других составов зависимости $\sigma^{\prime}(f)$ качественно подобны.

Во многих аморфных полупроводниках и диэлектриках проводимость в электрическом поле имеет вид [10]

$$
\sigma^{\prime}(\omega)=A \omega^{s}
$$

Линейный рост $\sigma^{\prime}$ с увеличением частоты (по степенно́му закону), свидетельствует о прыжковом механизме проводимости. Переход от частотно-независимой к частотно-зависимой области означает начало релаксации проводимости [11].

В области низких частот $\left(f<10^{1} \mathrm{~Hz}\right)$ в материале активировано максимальное число процессов поляризации, при этом пространственное движение заряженных частиц в почти постоянном (квазистационарном) электрическом поле ограничено потенциальными барьерами и дефектами структуры, которые препятствуют переносу электрических зарядов от электрода к электроду. При

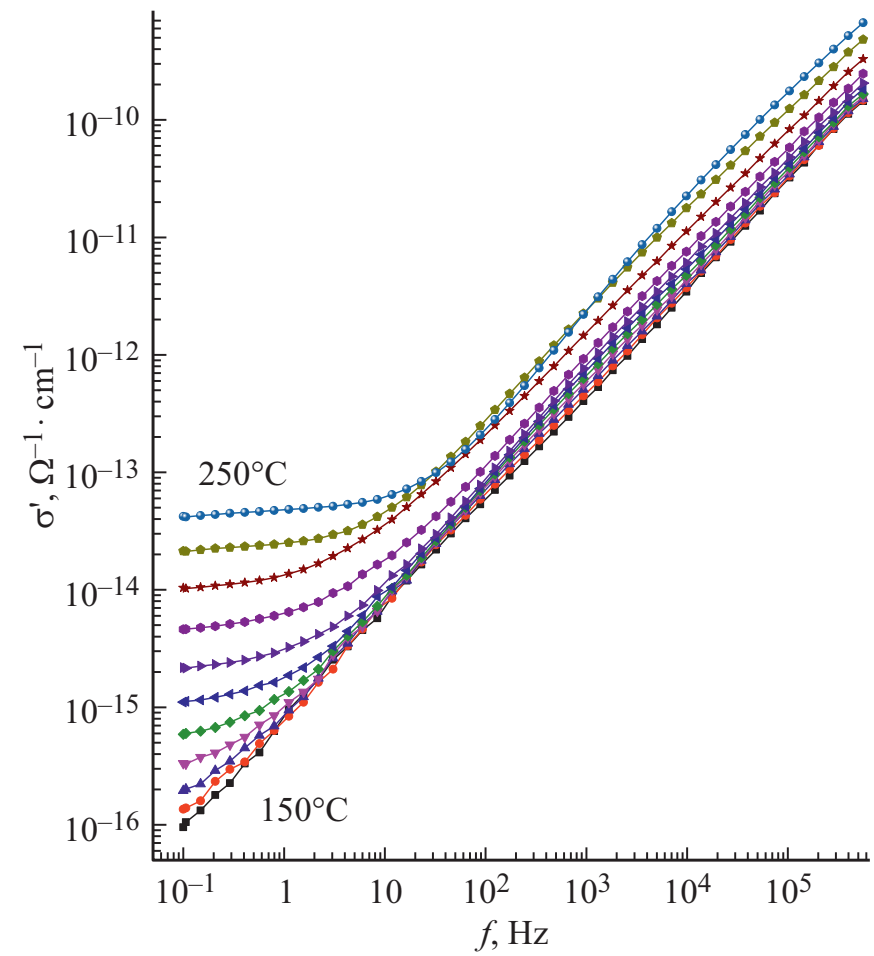

Pис. 1. Зависимость действительной части комплексной проводимости от частоты переменного поля при температурах от 150 до $250^{\circ} \mathrm{C}$ для ПФО/ $\mathrm{C}_{60(1 \%)}$. Температурный шаг равен $10^{\circ} \mathrm{C}$.

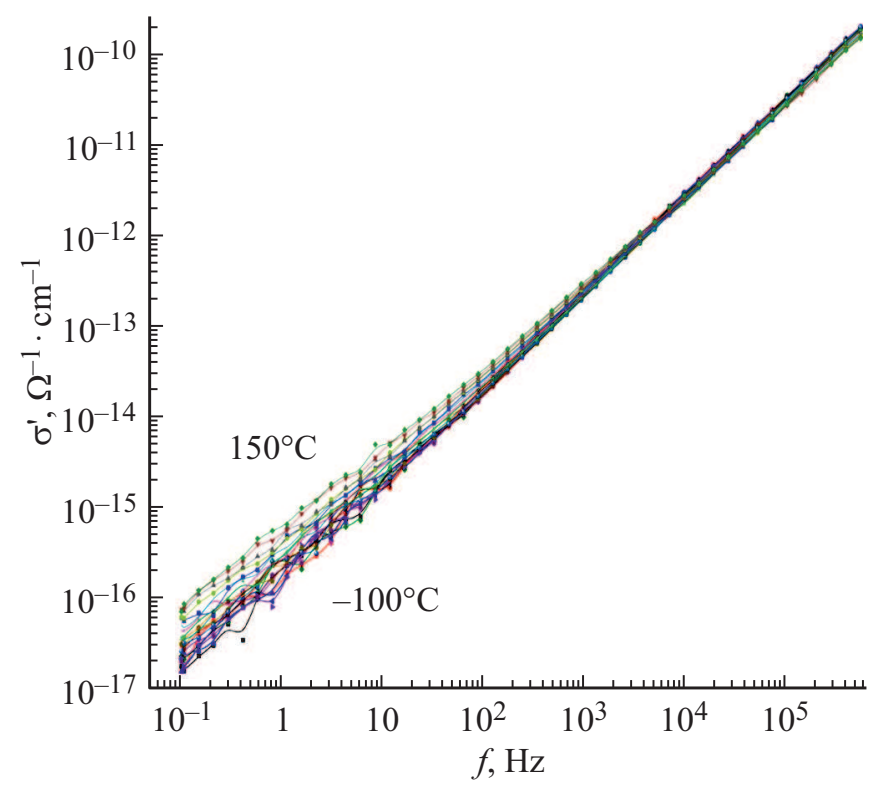

Рис. 2. Зависимость действительной части комплексной проводимости от частоты переменного поля при температурах от -100 до $150^{\circ} \mathrm{C}$ для ПФО/С $\mathrm{C}_{60(1 \%)}$. Температурный шаг равен $10^{\circ} \mathrm{C}$.

повышении частоты электрического поля заряженные частицы не успевают ориентироваться и, непрерывно следуя за изменением электрического поля, дают вклад 
в проводимость. Одновременно „выключается“ их вклад в поляризацию, что проявляется в уменьшении (дисперсии) диэлектрической проницаемости [8,9]. Данное явление называется релаксацией проводимости.

Непрерывный рост проводимости в очень широком интервале частот (от $10^{1} \mathrm{~Hz}$ ) объясняется разницей в величинах потенциальных барьеров, которые требуется преодолеть заряженным частицам для рекомбинации, из-за отсутствия какого-либо порядка в полимерном материале. Следует ожидать, что при более высоких частотах зависимость $\sigma^{\prime}(f)$ снова выйдет на „плато“. Это будет означать, что все переносчики заряда не успевают достигнуть локализованных состояний, а, следовательно, станут участвовать в переносе заряда - проводимость в материале достигнет максимума.

Очевидно, что проводимость в исследуемых материалах зависит также и от температуры. Однако влияние температуры является более явным в низкочастотном диапазоне, тогда как в области высоких частот значения $\sigma^{\prime}$ близки для разных температур и составляют $\approx 10^{-10} \Omega^{-1} \mathrm{~cm}^{-1}$, свидетельствуя о том, что исследуемые материалы лежат на границе между полупроводниками с проводимостью $\sigma=10^{4}-10^{-10} \Omega^{-1} \mathrm{~cm}^{-1}$ и диэлектриками с $\sigma=10^{-10}-10^{-22} \Omega^{-1} \mathrm{~cm}^{-1}$.

Переход от частотно-независимой части спектра к частотно-зависимой происходит при частоте $f_{0}$ и свидетельствует о начале релаксации проводимости. С повышением температуры значение $f_{0}$ сдвигается в область высоких частот, что связано с уменьшением потенциального барьера между локализованными состояниями носителей заряда. Как видно из рис. 1, релаксация проводимости при температуре $250^{\circ} \mathrm{C}$ начинается уже при частоте $f_{0}=3 \cdot 10^{1} \mathrm{~Hz}$. С понижением температуры уже при $150^{\circ} \mathrm{C}$ вышеупомянутый переход исчезает, и на графике остается только частотно-зависимая область спектра (рис. 2).

Динамика изменения значения показателя степени $s$ (формула (1)) от температуры является важным фактором при определении типа проводимости в материале. В случае квантово-механического туннелирования (QMT) показатель степени $s$ растет с повышением температур [12]; в рамках модели классического прыжкового механизма через потенциальный барьер (НОВ) $s=1$ [13]; в модели коррелированных прыжков (СВН) через потенциальный барьер $s$ уменьшается с ростом температуры [14]. В полимерных материалах чаще всего наблюдаются две модели переноса заряда: квантовомеханическое туннелирование и коррелированные прыжки через потенциальный барьер.

Согласно модели СВН (correlated barrier hopping), в электрическом поле электроны совершают прыжки, преодолевая потенциальный барьер

$$
W=W_{\mathrm{M}}-\frac{n e^{2}}{\pi \varepsilon \varepsilon_{0} r},
$$

где $W_{\mathrm{M}}$ - максимальная высота потенциального барьера, $\varepsilon$ - диэлектрическая проницаемость материала,

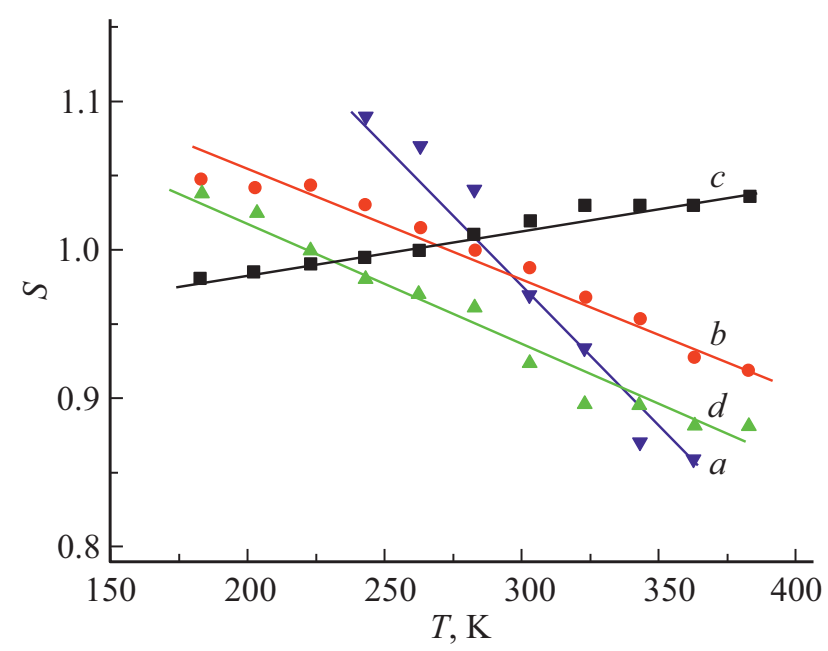

Рис. 3. Зависимость показателя степени $s$ от температуры для образцов чистого ПФО $(a)$, ПФО/С $60(1 \%)(b)$, $\Pi \Phi \mathrm{F} / \mathrm{Fe} @ \mathrm{C}_{60(1 \%)}(c), \Pi \Phi \mathrm{O} / \mathrm{C}_{60(8 \%)}(d)$.

$\varepsilon_{0}$ - диэлектрическая проницаемость вакуума, $r$ расстояние между двумя положениями носителя заряда, $n$ - число электронов, совершающих прыжок ( $n$ принимает значения 1 и 2 для случаев поляронного и биполяронного процессов соответственно).

В рамках модели СВН выражение для проводимости на переменном токе имеет вид

$$
\sigma^{\prime}(\omega)=\frac{\pi^{3} N^{2} \varepsilon \varepsilon_{0} \omega R_{\omega}^{6}}{24}
$$

Здесь $N$ - плотность пар состояний, между которыми совершают прыжки носители заряда.

Связь между длиной прыжка $R_{\omega}$ и высотой потенциального барьера выражается соотношением

$$
R_{\omega}=\frac{e^{2}}{\pi \varepsilon \varepsilon_{0}}\left[W_{\mathrm{M}}-k T \ln \left(\frac{1}{\omega \tau_{0}}\right)\right]^{-1} .
$$

С другой стороны, показатель степени $s$ связан с высотой потенциального барьера $W_{\mathrm{M}}$ выражением

$$
s=1-\frac{6 k T}{\left[W_{\mathrm{M}}-k T /\left(\omega \tau_{0}\right)\right]} .
$$

Формулу (5) можно упростить в первом приближении

$$
s=1-\frac{6 k T}{W_{\mathrm{M}}} .
$$

С целью выявления типа проводимости в исследуемых материалах, значения показателя степени $s$ были рассчитаны путем линейной аппроксимации экспериментальных кривых (рис. 2); зависимости показателя степени $s$ от температуры представлены на рис. 3.

Из рис. 3 видно, что для чистого ПФО (a),

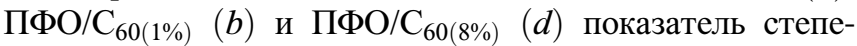
ни $s$ уменышается с ростом температуры. Для ПФО 
Таблица 1. Значение параметров переноса заряда в чистом ПФО

\begin{tabular}{c|c|c|c|c|c}
\hline$t,{ }^{\circ} \mathrm{C}$ & $f, \mathrm{~Hz}$ & $s$ & $N, \mathrm{~m}^{-3} \cdot 10^{22}$ & $R_{\omega}, \mathrm{m} \cdot 10^{-10}$ & $W_{\mathrm{M}}, \mathrm{eV}$ \\
\hline \multirow{3}{*}{100} & $1.1 \cdot 10^{6}$ & & 10.1 & 28.4 & \\
& 9838.8 & 0.88 & 6.9 & 32.6 & 1.5 \\
& 1.5 & & 4.7 & 44.8 & \\
\hline \multirow{3}{*}{50} & $1.1 \cdot 10^{6}$ & & 10.0 & 28.2 & \\
& 9838.8 & 0.90 & 5.9 & 31.5 & 1.6 \\
& 1.5 & & 5.9 & 40.6 & \\
\hline \multirow{3}{*}{30} & $1.1 \cdot 10^{6}$ & & 213.1 & 10.2 & \\
& 9838.8 & 0.96 & 133.7 & 10.5 & 3.7 \\
& 1.5 & & 225.2 & 11.2 &
\end{tabular}

Таблица 2. Значение параметров переноса заряда в композите $П Ф О / \mathrm{C}_{60(1 \%)}$

\begin{tabular}{c|c|c|c|c|c}
\hline$t,{ }^{\circ} \mathrm{C}$ & $f, \mathrm{~Hz}$ & $s$ & $N, \mathrm{~m}^{-3} \cdot 10^{22}$ & $R_{\omega}, \mathrm{m} \cdot 10^{-10}$ & $W_{\mathrm{M}, \mathrm{eV}}$ \\
\hline \multirow{3}{*}{100} & $1.1 \cdot 10^{6}$ & & 44.0 & 13.8 & \\
& 9838.8 & 0.92 & 41.9 & 14.9 & 2.4 \\
& 1.5 & & 36.6 & 17.7 & \\
\hline \multirow{3}{*}{50} & $1.1 \cdot 10^{6}$ & & 233.1 & 8.1 & \\
& 9838.8 & 0.95 & 216.2 & 8.4 & 3.7 \\
& 1.5 & & 200.6 & 9.2 & \\
\hline \multirow{3}{*}{30} & $1.1 \cdot 10^{6}$ & & 3537.0 & 2.1 & \\
& 9838.8 & 0.99 & 12132.1 & 2.1 & 13.1 \\
& 1.5 & & 13586.6 & 2.2 &
\end{tabular}

Таблица 3. Значение параметров переноса заряда в композите $\Pi Ф О / \mathrm{C}_{60(8 \%)}$

\begin{tabular}{c|c|c|c|c|c}
\hline$t,{ }^{\circ} \mathrm{C}$ & $f, \mathrm{~Hz}$ & $s$ & $N, \mathrm{~m}^{-3} \cdot 10^{22}$ & $R_{\omega}, \mathrm{m} \cdot 10^{-10}$ & $W_{\mathrm{M}, \mathrm{eV}}$ \\
\hline \multirow{3}{*}{100} & $1.1 \cdot 10^{6}$ & & 3.9 & 36.4 & \\
& 9838.8 & 0.86 & 1.4 & 43.7 & 1.3 \\
& 1.5 & & 1.7 & 69.0 & \\
\hline \multirow{3}{*}{50} & $1.1 \cdot 10^{6}$ & & 53.2 & 15.5 & \\
& 9838.8 & 0.93 & 22.6 & 16.5 & 2.5 \\
& 1.5 & & 38.2 & 18.9 & \\
\hline \multirow{3}{*}{30} & $1.1 \cdot 10^{6}$ & & 608.9 & 6.7 & \\
& 9838.8 & 0.97 & 316.6 & 6.9 & 5.2 \\
& 1.5 & & 517.3 & 7.2 &
\end{tabular}

с эндоэдральным фуллереном обнаруживается сравнительно медленный рост показателя $s$ с увеличением температуры.

Можно полагать, что образцам ПФО/С $60(1 \%)$, чистому ПФО и ПФО/С $60(8 \%)$ соответствует модель $\mathrm{CBН}$.

Из формул (2)-(6) рассчитаны значения параметров $N, R_{\omega}$ и $W_{\mathrm{M}}$ при разных температурах для исследуемых образцов (см. таблицы 1-3). Получено, что высота потенциального барьера уменьшается с повышением температуры.
В отличие от чистого ПФО, ПФО/С $60(1 \%)$ и ПФО/ $\mathrm{C}_{60(8 \%)}$, пленка ПФО/Fe $@ \mathrm{C}_{60(1 \%)}$ обнаруживает рост показателя степени $s$ с повышением температуры, что наблюдается в рамках модели квантово-механического туннелирования (QMT). Молекулярный механизм такого поведения требует дальнейшего изучения.

Как уже говорилось ранее, в большинстве полимеров, включая ПФО, наблюдаются оба механизма переноса заряда, однако один всегда является преобладающим. В данной работе обнаружено, что при введении атома железа в фуллерен в композиционном материале наблюдаются изменения, в результате которых происходит смена лидирующего типа проводимости, т. е. переход от прыжков носителей заряда через потенциальный барьер к квантово-механическому туннелированию. Это может быть вызвано ярко выраженными металлическими свойствами железа. Атом железа, инкапсулированный в молекулу фуллерена, выполняет роль электродонора. Атомы металла передают свои валентные электроны на внешнюю поверхность фуллереновой оболочки, тем самым изменяя общий заряд частиц наполнителя.

\section{4. Заключение}

В результате исследования процессов переноса электрического заряда в нанокомпозитах на основе ПФО с фуллереном и эндометаллофуллереном обнаружен переход от частотно-независимой к частотно-зависимой области на зависимостях $\sigma^{\prime}(f)$, при котором начинается процесс релаксации проводимости. Проводимость в образцах ПФО и в ПФО с фуллереном носит преимущественно прыжковый характер, т. е. согласуется с моделью прыжков через потенциальный барьер (CBH). В случае внедрения $\mathrm{Fe}$ в $\mathrm{C}_{60}$ тип проводимости меняется; в материале начинает преобладать перенос заряда за счет квантово-механического туннелирования. Для образцов $\Pi Ф О / \mathrm{C}_{60(1 \%)}$, чистого ПФО и ПФО/С $60(8 \%)$ рассчитаны значения параметров переноса заряда. Обнаружено, что высота потенциального барьера, который преодолевают заряженные частицы, следуя за электрическим полем, уменьшается с повышением температуры. Самые высокие значения высоты потенциального барьера WM соответствуют составу ПФО/С $60(1 \%)$, когда наполнитель находится в матрице полимера в молекулярно-диспергированном виде, а между молекулами полимера и наполнителя наблюдается химическая связь.

\section{Финансирование работы}

Работа выполнена в рамках государственного задания при финансовой поддержке Министерства просвещения России (проект № FSZN-2020-0026).

\section{Конфликт интересов}

Авторы заявляют, что у них нет конфликта интересов. 


\section{Список литературы}

[1] А.Ю. Пулялина, В.А. Ростовцева, Л.В. Виноградова, Г.А. Полоцкая. Мембраны и мембранные технологии 8, 2, 93 (2018).

[2] В.М. Юдович, М.Е. Юдович, А.М. Тойкка, А.Н. Пономарёв. Вестн. Санкт-Петербургского ун-та. Сер. 4. Физика. Химия 3, 59 (2009).

[3] Г.А. Полоцкая, С.В. Гладченко, А.В. Пенькова, В.М. Кузнецов, А.М. Тойкка. ЖПХ 78, 9, 1493 (2005).

[4] Ю.А. Михайлин. Термоустойчивые полимеры и полимерные материалы. Изд-во „Профессия“, СПб (2006). 624 с.

[5] П.Н. Лавренко, Н.П. Евлампьева, Д.М. Волохова, Л.В. Виноградова, Е.Ю. Меленевская, В.Н. Згонник. Высокомолекулярн. соединения А 44, 2, 289 (2002).

[6] Л.А. Шибаев, И.М. Егоров, В.Н. Згонник. Высокомолекулярн. соединения А 43, 1, 211 (2001).

[7] Ю.Ф. Бирюлин, Е.Ю. Меленевская, С.Н. Миков, С.Е. Орлов, В.Д. Петриков, Д.А. Сыкманов, В.Н. Згонник. ФТП 37, 1, 110 (2003).

[8] N.A. Nikonorova, A.A. Kononov, G.A. Polotskaya, R.A. Castro. Polymer Sci. A 62, 2, 116 (2020).

[9] N.A. Nikonorova, G.A. Polotskaya, A.A. Kononov, B.R. Hinderliter, K.L. Levine, R.A. Castro. J. Non-Cryst. Solids 483, 99 (2018).

[10] N.F. Mott. Electronic processes in non-crystalline solids. Clarendon, Oxford (1979). 465 p.

[11] J. Colmenero. Phys. Rev. Lett. 69, 3, 478 (1992).

[12] A.R. Long. Adv. Phys. 31, 5, 553 (1982).

[13] M. Pollak. Phys. Rev. Lett. 28, 22, 1449 (1972).

[14] G.E. Pike. Phys. Rev. B 6, 4, 1572 (1972).

Редактор Е.В. Толстякова 